\title{
STANDARDIZATION OF SIDDHA HERBOMINERAL FORMULATION “LINGA MATHIRAI”
}

\author{
SHANUVAS A*, INDHUMATHI M
}

Deparment of Gunapadam, Government Siddha Medical College, Arumbakkam, Chennai, Tamil Nadu. Email: dr.shanuvas@gmail.com

Received: 09 February 2017, Revised and Accepted: 27 March 2018

\begin{abstract}
Objective: Linga Mathirai is traditional Siddha medicine. The medicinal plants and the herbal preparations are preferred; nowadays, due to minimal side effects and the presence of abundant antioxidants and micronutrients which possesses a better therapeutic efficiency. According to the World Health organization, the herbal medicines have been defined as those containing plant parts or plant materials in raw state or processed form containing active principles. The Siddha system of medicine encompasses around 600 medicinal plants in materia medica.
\end{abstract}

Methods: Physicochemical analysis such as $\mathrm{pH}$, ash values, and loss on drying is done and biochemical analysis of acid and basic radicals. Instrumental analysis of Fourier transform-infrared (FT-IR) for analyze the functional groups in the test drug, scanning electron microscope (SEM) for determine the particle size of the drug, and inductively coupled plasma-optic emission spectrometry (ICP-OES) for heavy metal analysis.

Result: For standardization, organoleptic characters were done in that $\mathrm{pH}$ is 7.6, ash value is $1.379 \%$, water-soluble ash is $0.294 \%$, acid-insoluble ash is $0.871 \%$, loss on drying in 105 is $0.483 \%$, and disintegration time is 23 min. The functional group were analyzed by FT-IR. Then, in SEM, it has nano and microparticles. Finally, in ICP-OES, heavy metals are in permissible limits.

Conclusion: This standardization helps this drug to develop in future and also to evaluate these drug scientifically by determine the toxicity of the drug and pharmacological effect.

Keywords: Standardization, Physicochemical, Fourier transform-infrared, Scanning electron microscope, Inductively coupled plasma-optic emission spectrometry.

(C) 2018 The Authors. Published by Innovare Academic Sciences Pvt Ltd. This is an open access article under the CC BY license (http://creativecommons. org/licenses/by/4. 0/) DOI: http://dx.doi.org/10.22159/ajpcr.2018.v11i6.25228

\section{INTRODUCTION}

The Siddha system of medicine is a prestigious system belonging to South India. According to Siddha system, medicine is a substance that helps to alleviate or eradicate the disease, gives strength to the body, and normalizes the functions of the body [1]. This ancient system of herbal medicines is being utilized by Indians and has also gained attention worldwide due to its long-term benefits in terms of overall wellness with no side effects [2]. Although many Siddha formulations mentioned in the literature have witnessed for the treatment for various diseases, there is striving for global acceptance due to lack of scientific validation and documentation, to overcome the limitations and ensure the quality, safety, and therapeutic efficacy modern methods can be incorporated [3]. Normally, raw drugs are submitted to series of processes such as purification, trituration, incineration, and calcination to get the end product. The standardization of the drugs will assess the quality control of the drugs. Standardization of drug is essential to exhibit conformation of its identity and determination of its purity, quality, and quantity [4]. The aim of this paper is to validate standardization of Linga Mathirai through organoleptic, biochemical, physicochemical, microbial load, and instrumental analysis.

\section{METHODS}

\section{Standardization of the drug}

The World Health Organization (WHO) has appreciated the importance of medicinal plants for public health care. The process of evaluating the quality and purity of herbomineral drugs by means of various parameters such as physical, chemical, and biological observation is called standardization. Standardization of this drug comes under the following categories:

- Physicochemical analysis

- Phytochemical analysis.

- Biochemical analysis.
Organoleptic evaluation

The organoleptic characters of the sample were evaluated which include evaluation of the formulation by its color, odor, size, etc.

\section{Physicochemical investigation}

Physicochemical studies such as total ash, water-insoluble ash, acidinsoluble ash, loss on drying at $105^{\circ} \mathrm{C}$, and $\mathrm{pH}$ were done at Central Research Institute, Chennai.

\section{Biochemical analysis}

The biochemical analysis was done to identify the acid and basic radicals present in the $L$. mathirai. Acid radicals are potassium, calcium, magnesium, ammonium, sodium, iron, Zinc, aluminum, copper, lead, mercury, and arsenic. Basic radicals are sulfate, phosphate, chloride, carbonate, nitrate, fluoride, and oxalate.

The extract is prepared by $5 \mathrm{~g}$ of L. mathirai was taken in a $250 \mathrm{ml}$ clean beaker and $50 \mathrm{ml}$ of distilled water was added, boiled well and allowed to cool and filtered in a $100 \mathrm{ml}$ volumetric flask and made up to $100 \mathrm{ml}$ with distilled water.

\section{Microbial load}

Availability of bacterial load

By agar plating technique

The plate count technique is one of the most routinely used procedures because of the enumeration of viable cells by this method [5].

This method is based on the principle that when material containing bacteria are cultured, every viable bacterium develops into a visible colony on a nutrient agar medium. The number of colonies, therefore, is the same as the number of organisms contained in the L. mathirai. 
Calculate the number of bacteria per $\mathrm{ml}$ of the original suspension as follows:

$$
\text { Organisms per millimetre }=\frac{\text { Number of colonies }(\text { average of } 3 \text { repeats })}{\text { Amount of plated } \times \text { dilution }}
$$

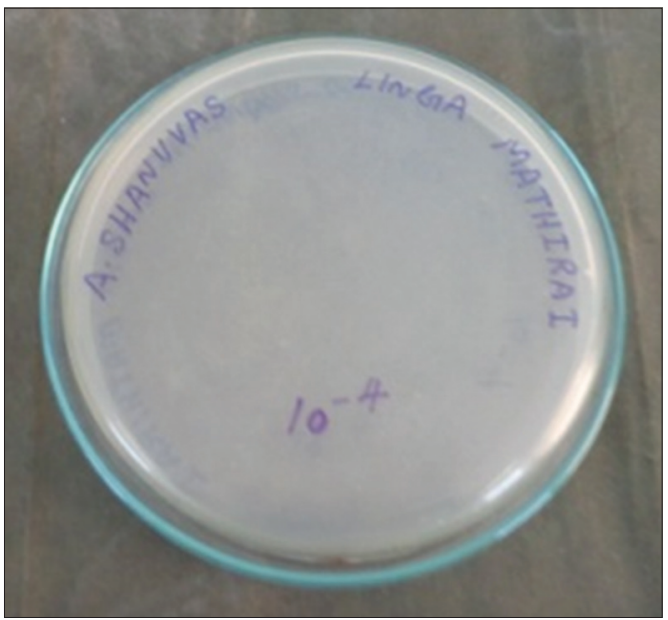

Fig. 1: $10^{-4}$ dilution (Bacteria)

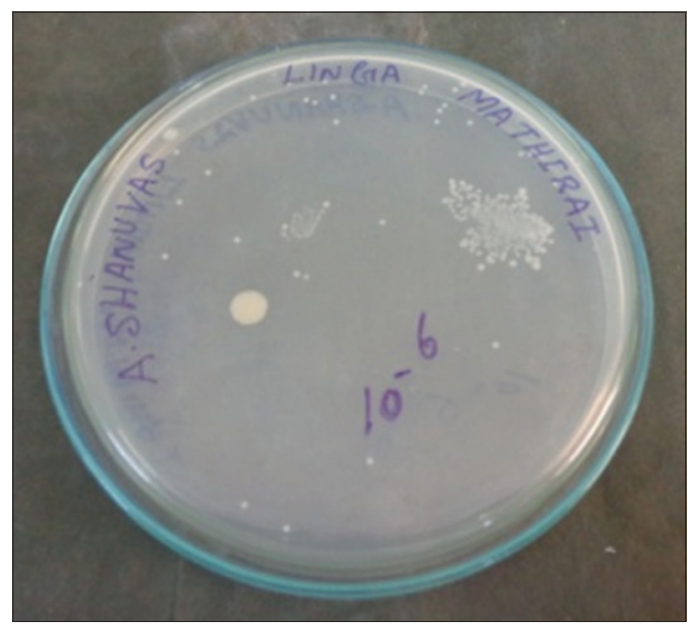

Fig. 2: $10^{-6}$ dilution (Bacteria)

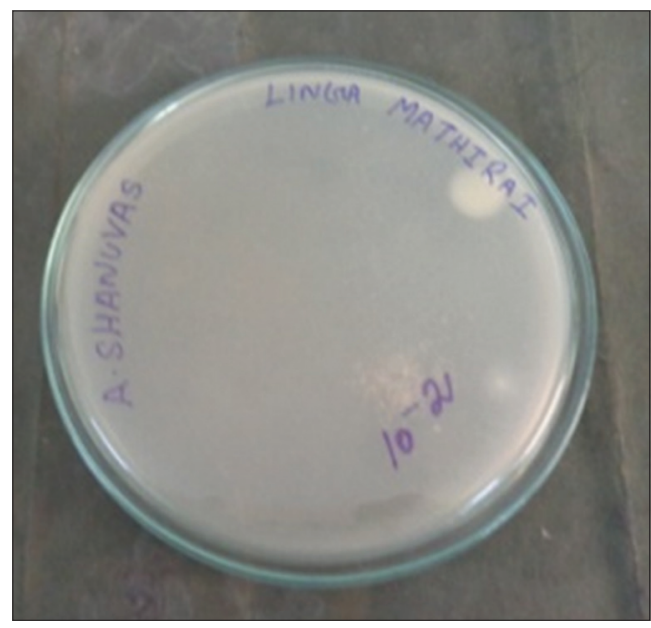

Fig. 3: 10-2 dilution (Fungi)
Instrumental analysis

Fourier transform-infrared (FT-IR)

It was the preferred method of infrared spectroscopy. FT-IR was an important and more advanced technique. It was used to identify the functional group, to determine the quality and consistency of the

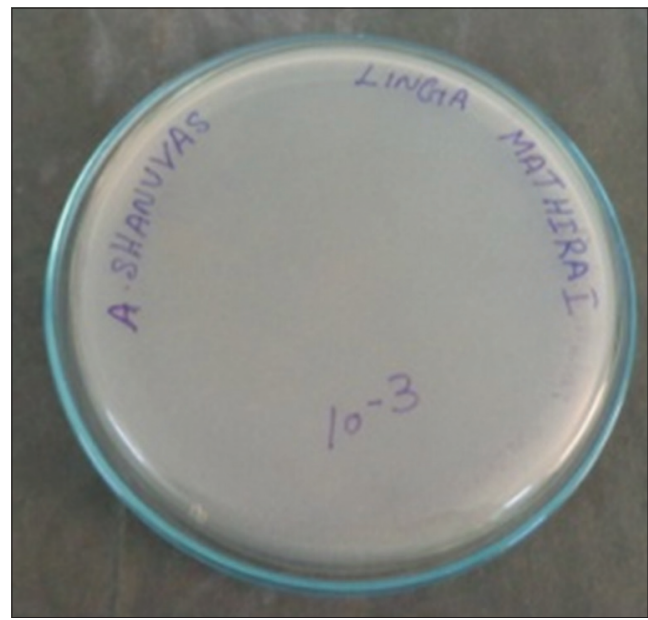

Fig. 4: $10^{-3}$ dilution (Fungi)

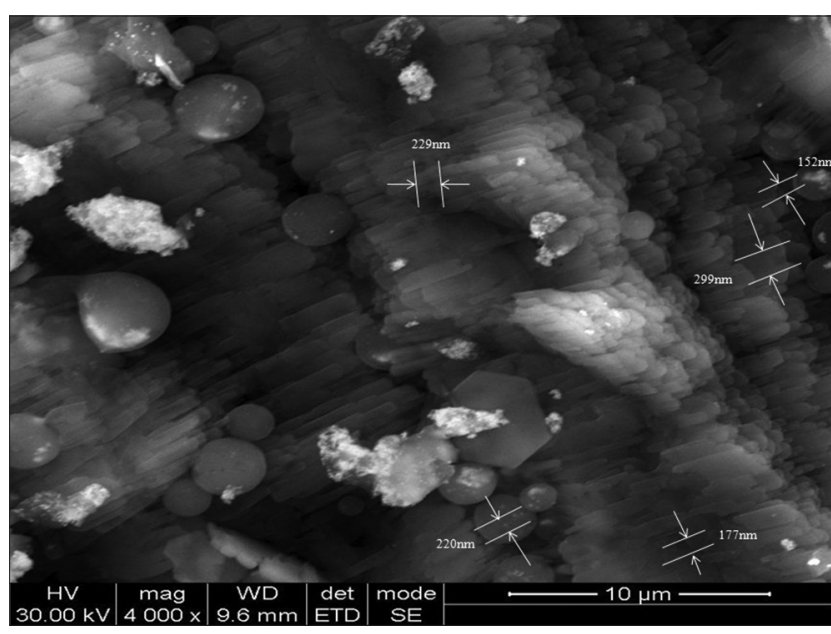

Fig. 5: Scanning electron microscope image of $10 \mu \mathrm{m}$

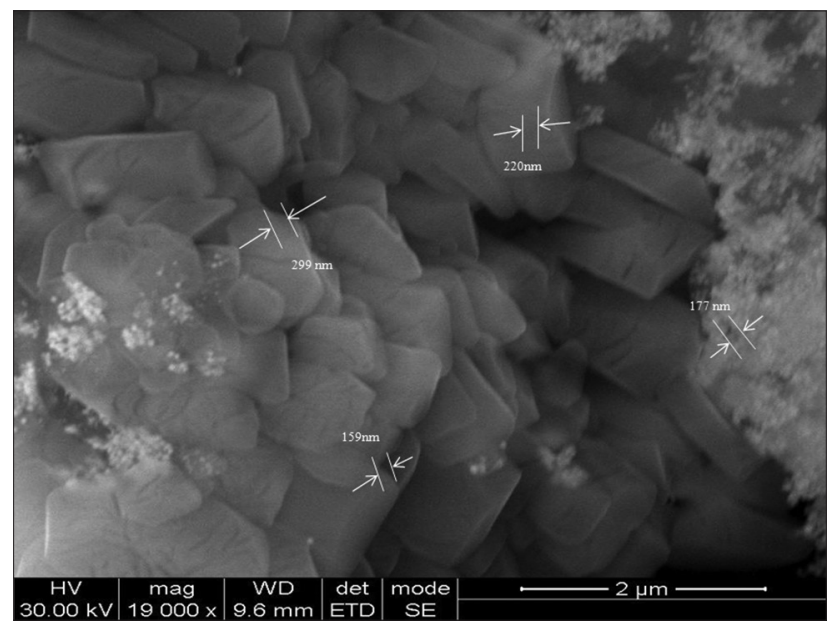

Fig 6: Scanning electron microscope image of $2 \mu \mathrm{m}$ 
sample material and can determine the amount of compounds present in the sample. It was an excellent tool for quantitative analysis [6].

In FT-IR, infrared was passed from a source through a sample (L. mathirai). This infrared was absorbed by the sample ( $L$. mathirai) according to the chemical properties and some are transmitted. The spectrum that appears denotes the molecular absorption and transmission. It forms the molecular fingerprint of the L. mathirai. Like the finger print, there were no two unique molecular structures producing the same infrared spectrum. It was recorded as the wavelength and the peaks seen in the spectrum indicates the amount of material present [7].

\section{Scanning electron microscope (SEM)}

In scanning electron microscope, high-energy electron beam was focused through a probe toward the sample (L. mathirai). Variety of signals was produced on interaction with the surface of the sample (L. mathirai). This results in the emission of electrons or photons, and it was collected by an appropriate detector [8].

This gives the information about the sample and it includes external morphology, texture, its crystalline structure, and chemical composition, and it displays the shape of the sample [9].

Inductively coupled plasma-optic emission spectrometry (ICP-OES) Mechanism

In plasma emission spectroscopy (OES), a L. mathirai solution was presented into the core of inductively coupled argon plasma (ICP), which generates temperature of approximately $8000^{\circ} \mathrm{C}$. At this

Table 1: Physical characterization of L. mathirai

\begin{tabular}{ll}
\hline Parameter & Results \\
\hline Color & Brick red \\
Odor & Odorless \\
Consistency & Hard \\
Shape & Spherical \\
State of matter & Solid \\
pH & 7.6 \\
Total ash $(\%)$ & 1.379 \\
Water-soluble ash $(\%)$ & 0.294 \\
Acid-insoluble ash $(\%)$ & 0.871 \\
Loss on drying at $105^{\circ} \mathrm{C}(\%)$ & 0.483 \\
Disintegration time $(\mathrm{min})$ & 23 \\
\hline
\end{tabular}

L. mathirai: Linga Mathirai temperature, all elements become thermally excited and emit light at their characteristic wavelengths. This light was collected by the spectrometer and passes through a diffraction grating that serves to resolve the light into a spectrum of its essential wavelengths. Within the spectrometer, this deflected light was then collected by wavelength and amplified to yield an strength of measurement that can be converted to an elemental concentration by comparison with standardization values [10].

The ICP-OES analysis was done in SAIF, IIT MADRAS, Chennai-36, using Perkin Elmer Optima 5300 DV.

\section{Sample preparation}

About $100 \mathrm{mg}$ L. mathirai was occupied in a clean, dry test tube. To this, $3 \mathrm{ml}$ nitric acid was added and mixed well and allowed for few minutes until the reactions were completed. And then, $25 \mathrm{ml}$ of refined water was added to prepare digested solution. The digested L. mathirai solution was shifted into plastic containers and labeled properly. It was completed in Biochemistry Laboratory, Government Siddha Medical College, Chennai-106.

\section{RESULT AND DISCUSSION}

\section{Organoleptic character}

Organoleptic character like $\mathrm{pH}$, water soluble ash, acid insoluble ash, loss on drying and disintegration time were tabulated [see Table 1]

\section{Discussion}

- $\quad$ pH of L. mathirai is 7.6. It is slightly alkaline in nature. The alkaline medium enhances the mineral storage to buffer, reduces aging process, and increases the utilization of oxygen level in body [11].

- The amount of minerals and earthy materials present in the drug is represented by total ash value. The value of L. mathirai is $1.379 \%$; it determines the purity of the drug.

- Water-soluble ash represents easy facilitation of diffusion and osmosis mechanism. Here, the value of L. mathirai is $0.294 \%$ will denote its diffusion capacity.

- The amount of siliceous matters in the drug is represented by acidinsoluble ash value. The acid-insoluble ash value of $L$. mathirai is $0.871 \%$, which determines the superior quality of the L. mathirai.

- The moisture content of the drug is determined by loss on drying. These will also indicate stability and shelf life of the drug. Here, the percentage denotes the higher stability of the L. mathirai.

- L. mathirai is formulated according to classical Siddha text; disintegration indicates the better solubility and absorbability of drug.

Table 2: Uniformity weight variation test result of $L$. mathirai

\begin{tabular}{|c|c|c|c|}
\hline $\begin{array}{l}\text { Weight of each } \\
\text { Mathirai (mg) }\end{array}$ & $\%$ of weight variation & Maximum weight variation with in $\pm 7.5 \%$ & Maximum weight variation with in $\pm 15.0 \%$ \\
\hline 138 & 5.423 & Yes & Yes \\
\hline 137 & 4.660 & Yes & Yes \\
\hline 132 & 0.840 & Yes & Yes \\
\hline 130 & -0.687 & Yes & Yes \\
\hline 139 & 6.187 & Yes & Yes \\
\hline 135 & 3.132 & Yes & Yes \\
\hline 129 & -1.451 & Yes & Yes \\
\hline 125 & -4.507 & Yes & Yes \\
\hline 133 & 1.604 & Yes & Yes \\
\hline 127 & -2.979 & Yes & Yes \\
\hline 128 & -2.215 & Yes & Yes \\
\hline 136 & 3.896 & Yes & Yes \\
\hline 124 & -5.271 & Yes & Yes \\
\hline 129 & -1.451 & Yes & Yes \\
\hline 135 & 3.132 & Yes & Yes \\
\hline 120 & -8.326 & No & Yes \\
\hline 122 & -6.799 & Yes & Yes \\
\hline 126 & -3.743 & Yes & Yes \\
\hline
\end{tabular}

Average: 130.95 g. L. mathirai: Linga Mathirai 


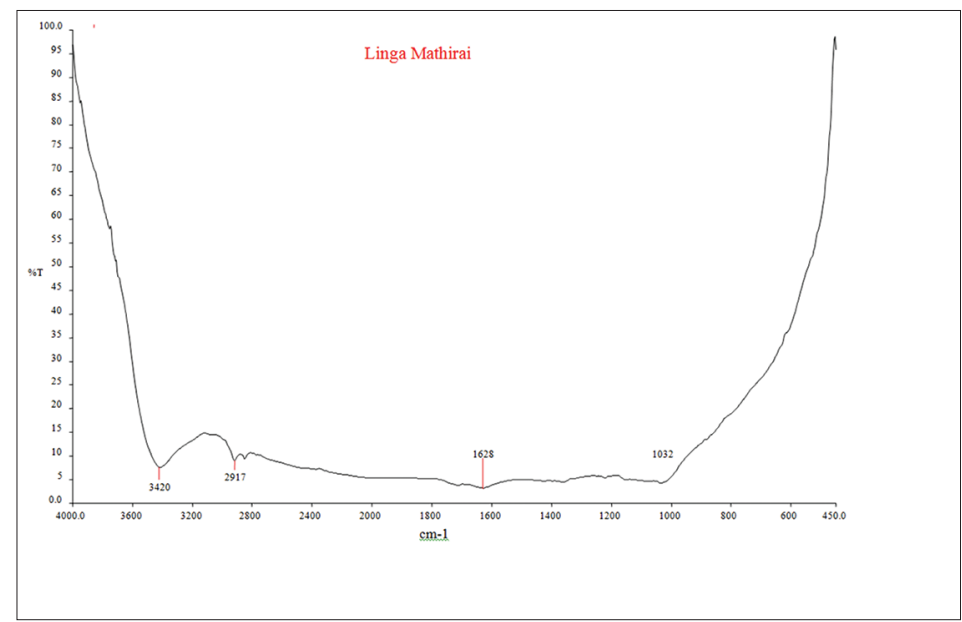

Table 3: Results for basic radicals

\begin{tabular}{lll}
\hline Parameter & Observation & Result \\
\hline Test for potassium & Yellow color precipitate & + ve \\
Test for calcium & - & - ve \\
Test for magnesium & - & - ve \\
Test for ammonium & - & - ve \\
Test for sodium & - & - ve \\
Test for iron (ferrous) & - & - ve \\
Test for zinc & - & - ve \\
Test for aluminum & - & - ve \\
Test for lead & - & - ve \\
Test for copper & - & - ve \\
Test for mercury & - & - ve \\
Test for arsenic & - & - ve \\
\hline
\end{tabular}

Table 4: Results for acid radicals

\begin{tabular}{lll}
\hline Parameter & Observation & Result \\
\hline Test for sulfate & $\begin{array}{l}\text { Formation of white } \\
\text { precipitate }\end{array}$ & + ve \\
Test for chloride & - & - ve \\
Test for phosphate & - & - ve \\
Test for carbonate & - & - ve \\
Test for fluoride and oxalate & - & - ve \\
Test for nitrate & - & - ve \\
\hline
\end{tabular}

\section{Table 5: FTIR result of L. mathirai}

\begin{tabular}{ll}
\hline $\begin{array}{l}\text { Characteristic absorption } \\
\text { (s) }\left(\mathbf{c m}^{-1}\right)\end{array}$ & Functional groups \\
\hline 3420 & $\begin{array}{l}\text { Alcoholic group normal } \\
\text { "polymeric" OH stretch } \\
\text { Amine group of N-H Bending } \\
\text { Alkane C-H stretch, acid group of } \\
\text { O-H stretch } \\
\text { Alkene group of C=C stretch, } \\
\text { amide group of N-H Bending } \\
\text { Alkyl halide C-F stretch, ether C-O } \\
\text { stretch, ester C-O stretch }\end{array}$ \\
1628 & \\
\hline
\end{tabular}

FTIR: Fourier transform-infrared, L. mathirai: Linga Mathirai

\section{Weight variation test}

The result of weight variation has been tabulated [see Table 2]

\section{Discussion}

- Average weight of the Mathirai was noted as 130.95 g. Of 20 tablets tested, 19 tablets of them lie within $\pm 7.5 \%$ weight variation $(1$ tablet
Table 6: ICP-OES result of L. mathirai

\begin{tabular}{ll}
\hline Elements & Detected levels \\
\hline Sulfur (mg/L) & 52.514 \\
Potassium (mg/L) & 20.821 \\
Calcium (mg/L) & 12.120 \\
Phosphorus (mg/L) & 08.541 \\
Mercury (mg/L) & 0.674 \\
Iron (mg/L) & 0.380 \\
Sodium (mg/L) & 03.110 \\
Arsenic & BDL \\
Cadmium & BDL \\
Nickel & BDL \\
Lead & BDL \\
\hline
\end{tabular}

ICP-OES: Inductively coupled plasma-optic emission spectrometry,

L. mathirai: Linga Mathirai

above the limit) and all 20 tablets lie within $\pm 15 \%$ weight variation.

- According to the limits of weight test cited in the Indian pharmacopoeia, L. mathirai passed the uniformity weight test.

- The uniformity test resembles uniformly distribution of this tablet helps good absorption and distribution.

Traditional test for pill

\begin{tabular}{ll}
\hline Character & Inference \\
\hline Non-sticky on rolling & + \\
No cracks over the surface after drying & + \\
Shall be rolled uniformly over the plane surface & + \\
\hline
\end{tabular}

\section{Biochemical analysis}

\section{Basic radicals}

Result of the basic radicals shows the presence of potassium and absence of other basic radicals which has been tabulated [see Table 3]

\section{Interpretation}

The basic radical test shows the presence of potassium and absence of heavy metals.

\section{Potassium}

The K+ inwardly rectifier channel is one of the two subunits of the pancreatic islet ATP-sensitive potassium channel complex (IKATP). It has a key role in glucose-stimulated insulin secretion and thus is a potential candidate for a genetic defect in Type II (non-insulindependent) diabetes mellitus [12].

\section{Acid radical}

Interpretation

The acidic radicals test shows the presence of sulfate [see Table 4]. 


\section{Microbial load}

Availability of bacterial and fungal load in L. mathirai was estimated by agar plating method, the results were discussed below

- The contaminated toxins present in the drug will produce adverse effect, which develops unwanted diseases. They are unfit for humans [13].

- Here, the contamination of L. mathirai has been examined by bacterial and fungal load.

- Total bacterial load in $10^{-4}$ dilution is 4 and in $10^{-6}$ dilution is nil.

- Total fungal load in $10^{-2}$ dilution is nil and in $10^{-3}$ dilution is nil [See Figs. 1 and 2].

- The load of bacterial and fungal is within the limits of the WHO norms [See Figs. 3 and 4].

\section{Instrumental analysis}

FTIR

The function group was analyzed by FTIR which has been tabulated [see Table 5].

\section{Discussion}

- The above table shows the presence of alcoholic group, amine group, alkane group, and alkyl halide group is the organic functional groups, also ether and ester group of carbonyl functional groups.

- $\quad \mathrm{OH}$ group has higher potential toward inhibitory activity against microorganisms.

Scanning electron microscopy

For the SEM result see Figs. 5 and 6.

\section{Discussion}

SEM picture shows nano and microparticle (Ultrafine particle) size of the sample. Moreover, the picture shows various sizes of the particles such as $152 \mathrm{~nm}, 177 \mathrm{~nm}, 220 \mathrm{~nm}, 229 \mathrm{~nm}$, and $299 \mathrm{~nm}$.

Sizes are ranging from $179 \mathrm{~nm}$ to $304 \mathrm{~nm}$. The surface of the sample grains is uniformly arranged. These are microparticles presenting as $152 \mathrm{~nm}, 177 \mathrm{~nm}, 220 \mathrm{~nm}, 229 \mathrm{~nm}$, and $299 \mathrm{~nm}$. The difference in morphology as evident from the micrograph is due to the presence of chemicals in the samples.

\section{Microparticles - significance}

- Microparticles are defined as particulate dispersion or solid particles with a size in the range of 100-1000 $\mathrm{nm}$ in diameter.

- $\quad$ Size and surface of microparticles can be easily manipulated to achieve both passive and active drug targeting.

- They control the release of drug during the transportation and at the site of localization, alter drug distribution in the body and subsequent clearance of the drug so as to achieve increased drug therapeutic efficacy, thereby bioavailability and reduced side effects [14].

\section{ICP-OES}

Heavy metals was analyzed by ICP-OES, results has been tabulated [see Table 6].

\section{Discussion}

- From the above results, the heavy metals such as arsenic, cadmium, and lead are below detectable limit.

- Mercury was in permissible limit.

- Hence, the safety of the drug L. mathirai is ensured.

- Furthermore, the drug contains calcium, iron, potassium, sodium, sulfur, and phosphorus.

\section{Calcium [15]}

- Calcium was associated with the lower risk of diabetes mellitus.

- Calcium is necessary in normalizing the glucose tolerance.

- Abnormal regulation of intracellular calcium affecting both insulin sensitivity and insulin release.

\section{Iron}

- The heme containing enzymes such as catalase and peroxidase protect cell against potentially damaging highly reactive species.
- Iron is essential for many numbers of biological functions such as growth, reproduction, healing, and immune function.

Sodium

- Recently, sodium glucose cotransporter 2 reabsorbs most of the glucose filtered by the kidneys. Thereby, lowering the blood glucose levels and has been approved as new antihyperglycemic drug [16].

- A synergistic effect of all these calcium, iron, potassium, sodium, phosphorus, and sulfur increases the potency of the drug against diabetes mellitus.

\section{CONCLUSION}

For standardization of $L$. mathirai, physical characterization such as $\mathrm{pH}$, total ash, water-soluble ash, acid-insoluble ash, loss on drying, disintegration is done. In acid and basic radical analysis, the presence of potassium and sulfate has been identified. In microbial load of bacterial and fungal is within the limits. In FT-IR, functional groups are identified. In SEM, the drug has both nano and microparticles which has increased drug efficacy and reduced side effects. In ICP-OES, safety of this drug is ensured by analysis of heavy metals which are in permissible limits. These results that $L$. mathirai have maximal efficacy and reduced adverse effect which helps in development of drug. Hence, the standardization of the drug is the first step for further assessing toxicological and validating pharmacological activities.

\section{CONFLICTS OF INTEREST}

The authors have declared no conflicts of interest.

\section{REFERENCES}

1. Sambasivampillai TV. Tamil to English Dictionary of Medicine. Vol 2. Chennai: The Research Institute of Siddhar's Science; 1931. p. 205.

2. Khan TA, Gohel AK, Mallya R. Standardisation and HPTLC method development of marketed Ayurvedic formulation-balarishta. Int $\mathrm{J}$ Pharm Pharm Sci 2016;8:201-9.

3. Punitha A, Visweswaran S, Muthukumar NJ, Murugesan M. Physicochemical evaluation and HPTLC finger print of Siddha poly herbal formulation "Swasa kudori mathirai". Int J Pharm Pharm Sci 2015;7:560-7.

4. World Health Organization. WHO Guidelines for Assessing Quality of Herbal Medicines with Reference to Contaminants and Residues. Geneva: WHO; 2007. http://www.apps.who.int/medicinedocs/ documents/s14878e/s14878e.pdf. [Last accessed on 2014 Jun 02].

5. Aneja KR. Practical Text Book of Microbiology. New Delhi: CBS Publisher and Distributors; 2005. p. 467.

6. Fourier Transform Infrared Spectroscopy (FT-IR). Analysis and Testing Chemical Compound. Available from: http://www.intertek.com/analysis/ftir.

7. FT-IR Sample Preparation. Northen Illinois University, Department of Chemistry and Bio-chemistry. Available from: http://www.niu.edu/ ANALYTICALLAB/ftir/samplepreparation.shtml.

8. Hearle JW, Sparrow JT, Cross PM. The Use of the Scanning Electron Microscope. Oxford: Pergamon Press Ltd; 1972. Available from: http:// www.SEM-EDX-GSR-ASPEX-09-05-2014.PDF.

9. Rachel B. Using the scanning electron microscope for discovery based learning in undergraduate course. J Geosci Educ 2004:52:250-25.

10. Montaser A, Golightly DW. Inductively Coupled Plasmas in Analytical Atomic Spectrometry. New York: VCH Publ; 1992. Available from: http://www.odp.tamu. edu/publication/tnotes/tn29/technot4.htm.

11. Berg BG. The Voice of Alternative Medicine. Acid-Alkaline Balance and its Importance. Available from: http:/www.burtongoldberg.com/ page 84.html.

12. Campbell A. Diabetes self Management. The power of Potassium; 2007. Available from: http://www.diabetesselfmanagement.com/ blogger/amy-campbell.

13. Richter SS. A general method for rapid determination of antibiotic. J Clin Microbiol. Available from: http://www.jcm.asm.org/content/53/2/425.

14. Robert A, Freitas J. Nanomedicine Biocompatibility. Vol. 2A; 2003. Available from: https://www.en.wikipedia.org/wiki/Nanomedicine.

15. Anastassios G, Pittas M, Dawson B. Vitamin D and Calcium Intake in Relation to Type 2 Diabetes. ADA; 2006. Available from: http://www. care.diabetesjournals.org/content/29/3/650.short.

16. Novikov A. Volker vallon. Sodium Glucose Cotransporter 2 Inhibition in the Diabetic Kidney; 2016. Available from: http://www.medscape. com/viewarticle/856279. 